\title{
Article \\ Association of ROX Index with Mechanical Ventilator Use in Sepsis Patients in the Emergency Department
}

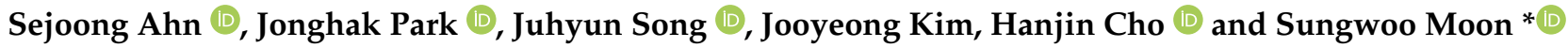 \\ Department of Emergency Medicine, Korea University Ansan Hospital, Ansan-si 15355, Korea; \\ sejoongahn@naver.com (S.A.); rosc@hanmail.net (J.P.); songcap97@gmail.com (J.S.); blj01he@gmail.com (J.K.); \\ chohj327@korea.ac.kr (H.C.) \\ * Correspondence: yg9912@korea.ac.kr; Tel.: +82-31-412-5380
}

check for updates

Citation: Ahn, S.; Park, J.; Song, J.; Kim, J.; Cho, H.; Moon, S. Association of ROX Index with Mechanical

Ventilator Use in Sepsis Patients in the Emergency Department. J. Clin Med. 2022, 11, 342. https:// doi.org/10.3390/jcm11020342

Academic Editor: Marcello Candelli

Received: 10 December 2021

Accepted: 9 January 2022

Published: 11 January 2022

Publisher's Note: MDPI stays neutral with regard to jurisdictional claims in published maps and institutional affiliations.

Copyright: (C) 2022 by the authors. Licensee MDPI, Basel, Switzerland. This article is an open access article distributed under the terms and conditions of the Creative Commons Attribution (CC BY) license (https:// creativecommons.org/licenses/by/ $4.0 /)$.

\begin{abstract}
Detecting sepsis patients who are at a high-risk of mechanical ventilation is important in emergency departments (ED). The respiratory rate oxygenation (ROX) index is the ratio of tissue oxygen saturation/fraction of inspired oxygen to the respiratory rate. This study aimed to investigate whether the ROX index could predict mechanical ventilator use in sepsis patients in an ED. This retrospective observational study included quick sequential organ failure assessment (qSOFA) $\geq 2$ sepsis patients that presented to the ED between September 2019 and April 2020. The ROX and ROX-heart rate $(\mathrm{HR})$ indices were significantly lower in patients with mechanical ventilator use within $24 \mathrm{~h}$ than in those without the use of a mechanical ventilator (4.0 [3.2-5.4] vs. 10.0 [5.9-15.2], $p<0.001$ and 3.9 [2.7-5.8] vs. 10.1 [5.4-16.3], $p<0.001$, respectively). The area under the receiver operating characteristic (ROC) curve of the ROX and ROX-HR indices were 0.854 and 0.816 (both $p<0.001$ ). The ROX and ROX-HR indices were independently associated with mechanical ventilator use within $24 \mathrm{~h}$ (adjusted hazard ratio $=0.78,95 \%$ CI: $0.68-0.90, p<0.001$ and adjusted hazard ratio $=0.87,95 \% \mathrm{CI}$ $0.79-0.96, p=0.004$, respectively). The 28-day mortality was higher in the low ROX and low ROX-HR groups. The ROX and ROX-HR indices were associated with mechanical ventilator use within $24 \mathrm{~h}$ in qSOFA $\geq 2$ patients in the ED.
\end{abstract}

Keywords: sepsis; emergency department; mechanical ventilator; ROX index

\section{Introduction}

Sepsis is a life-threatening condition that results from a dysregulated host response to infections [1]. Sepsis is one of the most common causes of mechanical ventilator use in intensive care units (ICUs) [2] and emergency departments (EDs) [3-5]. Mechanical ventilation is a key component in managing patients with intubated sepsis [6-8].

The respiratory rate oxygenation (ROX) index is the ratio of tissue oxygen saturation $\left(\mathrm{SpO}_{2}\right)$ / fraction of inspired oxygen $\left(\mathrm{FiO}_{2}\right)$ to the respiratory rate (RR) [9]. Previous studies have reported that the ROX index can be used to predict the need for mechanical ventilator use in patients with hypoxemic acute respiratory failure using a high-flow nasal cannula in ICUs $[9,10]$. The ROX-heart rate (HR) index is a modified ROX index that includes the heart rate and ROX index. A previous study used the ROX-HR index to identify mechanical ventilator use in patients with hypoxemic acute respiratory failure using a high-flow nasal cannula in the ICU [11].

The usefulness of the ROX index in EDs remains unclear. A previous study reported that a low ROX index in the ED could predict mortality in sepsis patients [12]. Identifying patients who are at a high-risk of mechanical ventilation is important for appropriate management. The role of the ROX or ROX-HR index in predicting the need for mechanical ventilator use regardless of the use of a high-flow nasal cannula in sepsis patients in EDs is not well studied. Thus, this study aimed to investigate whether the ROX index or ROX-HR index could predict mechanical ventilator use in quick sequential organ failure assessment (qSOFA) $\geq 2$ sepsis patients in an ED. 


\section{Materials and Methods}

\subsection{Study Design and Setting}

This retrospective observational study was performed at the Korea University Ansan Hospital, the only tertiary academic teaching hospital in Ansan-si. Approximately 50,000 patients visit the ED of Korea University Ansan Hospital each year [13]. This study was approved by the institutional review board (IRB) of Korea University (2021AS0057). Due to its retrospective design, the requirement for informed consent was waived by the IRB.

\subsection{Definitions}

The qSOFA score was used for screening sepsis and considered whether the patient's $R R \geq 22 / \mathrm{min}$, whether the patient's Glasgow Coma Scale (GCS) score $<15$, and whether the patient's systolic blood pressure $\leq 100 \mathrm{mmHg}$ [1]. The qSOFA score was considered "qSOFA-positive" if two or more components were positive. The sequential organ failure assessment (SOFA) score was used to diagnose sepsis and composed of six categories (respiration, coagulation, liver, cardiovascular, central nervous system, and renal system evaluations) with scores ranging from 0 to 4 for each category. An increase of two or more SOFA scores from the patient's baseline or qSOFA positive due to infection was defined as sepsis [1]. Septic shock was defined as a lactic acid level $\geq 2 \mathrm{mmol} / \mathrm{L}$ and vasopressor use to maintain a mean arterial pressure $\geq 65 \mathrm{mmHg}$ despite adequate fluid resuscitation [1]. All patients were managed according to the Surviving Sepsis Campaign guidelines [1,6].

Whether the patient was diagnosed as sepsis or not and primary infection focus was determined by the board-certified emergency physicians or infection specialist by reviewing all medical records and investigations.

The ROX index was defined as the ratio of tissue oxygen saturation $\left(\mathrm{SpO}_{2}\right) /$ fraction of inspired oxygen $\left(\mathrm{FiO}_{2}\right)$ to RR [9]. ROX-HR was defined as the ROX index over HR/100 [11].

$$
\begin{aligned}
\text { ROX index } & =\left(\mathrm{SpO}_{2}\right) /\left(\mathrm{FiO}_{2} \times \mathrm{RR}\right) \\
\text { ROX-HR index } & =(\text { ROX index } \times 100) / \mathrm{HR}
\end{aligned}
$$

$\mathrm{FiO}_{2}$ was calculated according to the methods of oxygen delivery [14]. A high concentration reservoir mask was used to supply oxygen when oxygen was delivered at flow rate of $10-15 \mathrm{~L} / \mathrm{min}$. The calculated $\mathrm{FiO}_{2}$ of patients using high concentration reservoir mask was ranged from 0.60 to 0.90 . A simple face mask was used to supply oxygen when oxygen was delivered at flow rate of 5-10 L/min. The calculated $\mathrm{FiO}_{2}$ of patients using simple face mask was ranged from 0.40 to 0.60 . A nasal prong was used to supply oxygen when oxygen was delivered at flow rate of $1-5 \mathrm{~L} / \mathrm{min}$. The calculated $\mathrm{FiO}_{2}$ of patients using nasal prong was ranged from 0.24 to 0.40 . We assumed that there are linear correlations between calculated $\mathrm{FiO}_{2}$ and delivered flow rate of oxygen for reservoir mask, simple mask, and nasal prong. When physicians decided to use a venturi mask or high-flow nasal cannula to deliver oxygen, $\mathrm{FiO}_{2}$ was defined as targeted oxygen concentration by venturi mask or high-flow nasal cannula [14].

Initial values after arrival at the ED were used to calculate the qSOFA score, SOFA score, ROX index, and ROX-HR index.

The mechanical ventilator use was defined as invasive mechanical ventilator use.

\subsection{Study Population}

From September 2019 to April 2020, adult patients (age $\geq 18$ years) that were qSOFApositive upon ED arrival and were diagnosed with sepsis were included. Patients who were under 18 years old, pregnant, arrived in cardiac arrest, had missing laboratory results needed to calculate the SOFA score or ROX index, had a do-not-resuscitate (DNR) order for mechanical ventilator or were not willing to be resuscitated with mechanical ventilator, or were in an intubated state or tracheostomy state before arrival to the ED were excluded. Patients who did not survive for more than $24 \mathrm{~h}$ were excluded as this might have affected the primary outcome. 


\subsection{Data Collection}

Patient data were obtained from the electronic medical records. Baseline characteristics of the patients, such as sex, age, and comorbidities, were collected. The patient's initial vital signs upon arrival to the ED, infection focus, laboratory results department, SOFA scores, vasopressor use, and septic shock status in the ED were collected.

The comorbidities of patients were classified as heart disease, lung disease, liver disease, kidney disease, cerebrovascular disease, and malignancy if they were diagnosed with congestive heart failure, prior myocardial infarction, or cardiomyopathy; chronic obstructive pulmonary disease or interstitial primary fibrosis; liver cirrhosis; chronic kidney disease; hemorrhagic or ischemic stroke; and active malignancy, respectively.

The infection focus was categorized into respiratory, central nervous system, gastrointestinal, genitourinary, skin and soft tissue, catheter-related, and bacteremia. Brain Natriuretic Peptide (BNP) elevation was defined as an elevation in the N-termial pro-BNP (NT-proBNP) or BNP levels.

\subsection{Outcomes}

The primary outcome was the use of mechanical ventilator within $24 \mathrm{~h}$ after ED arrival. The secondary outcomes were 7-day mortality, 14-day mortality, 28-day mortality, and ICU admission.

\subsection{Statistical Analysis}

Continuous variables were expressed as means and standard deviations when the variables were normally distributed or medians and interquartile ranges when the variables were not normally distributed. Continuous variables were compared using Student's $t$-test or the Mann-Whitney test according to the distribution of variables. Categorical variables were expressed as numbers and percentages and were evaluated using the chi-square test or Fisher's exact test. The receiver operating characteristic (ROC) curve of the ROX index and ROX-HR index predicting the primary outcome was performed to determine the area under the curve, sensitivity, and specificity. The Youden index was used to determine the optimal cutoff point. The primary outcome and secondary outcomes by ROX and ROX-HR indices levels according to the cutoff points were evaluated. When evaluating associations of 7-day, 14-day, and 28-day mortality with ROX and ROX-HR indices levels according to the cutoff points, the patients who died within $24 \mathrm{~h}$ were included in analysis to reduce selection bias. Kaplan-Meier analysis and the log-rank test were performed to compare mechanical ventilator use within $24 \mathrm{~h}$ by ROX and ROX-HR indices levels according to the cutoff points. The Cox proportional hazard model was performed to find factors associated with mechanical ventilator use within $24 \mathrm{~h}$. The factors that were significant at a level of 0.1 and those selected by the researchers were used in a stepwise backward elimination multivariate Cox proportional hazard model (Supplementary Table S1). Subgroup analysis according to infection focus was performed. A $p$-value of less than 0.05 was considered significant. Statistical analyses were performed using $\mathrm{R}$ version 4.0.2 ( $\mathrm{R}$ Foundation for Statistical Computing, Vienna, Austria).

\section{Results}

During the study period, 186 patients were qSOFA-positive with a diagnosis of sepsis or septic shock. Forty-nine patients were excluded due to: missing laboratory data (18 patients), intubated or tracheostomy state before arrival at the ED (16 patients), DNR order or unwillingness to be resuscitated (15 patients), and death within $24 \mathrm{~h}$ (6 patients). Finally, 131 patients were included (Figure 1 ). 


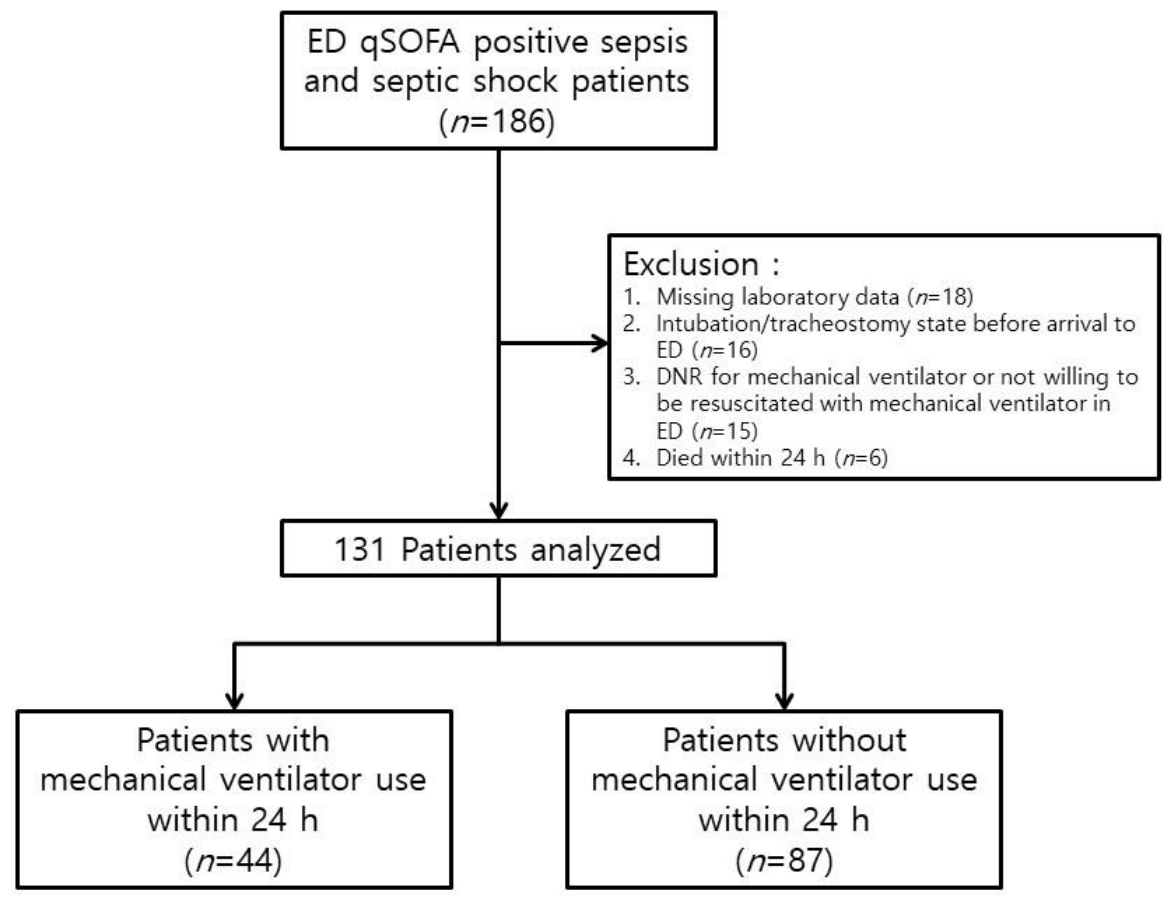

Figure 1. Flow chart of the study population. Abbreviations: ED = emergency department, qSOFA = quick sequential organ failure assessment, DNR = do-not-resuscitate.

\subsection{Baseline Characteristics}

Of 131 patients, the mean age was $75.0 \pm 12.5$, and 75 (57.3\%) were male. The mean SOFA score was 8.8 , and $55(42.0 \%)$ patients were diagnosed with septic shock. Respiratory infection was the most frequent primary infection focus in the study population. None of the patients were diagnosed with COVID-19.

Table 1 shows the baseline and clinical characteristics according to the use or non-use of mechanical ventilator within $24 \mathrm{~h}$. The ROX and ROX-HR indices were significantly lower in patients with mechanical ventilator use within $24 \mathrm{~h}$ than in patients without the use of a mechanical ventilator (4.0 [3.2-5.4] vs. 10.0 [5.9-15.2], $p<0.001$ and 3.9 [2.7-5.8] vs. 10.1 [5.4-16.3], $p<0.001$, respectively). $\mathrm{SpO}_{2}, \mathrm{pH}, \mathrm{PO}_{2}$, and $\mathrm{PaO}_{2} / \mathrm{FiO}_{2}$ ratio were significantly lower in patients with mechanical ventilator use within $24 \mathrm{~h}$ than in those without. The SOFA score, SOFA without respiration score, septic shock status, RR, lactate level, $\mathrm{PCO}_{2}$, vasopressor use, and applied $\mathrm{FiO}_{2}$ were statistically higher in patients with mechanical ventilator use within $24 \mathrm{~h}$ than in those without. There was no statistical difference in the use of a high-flow nasal cannula between the two groups.

Table 1. Baseline and clinical characteristics of the study population.

\begin{tabular}{cccc}
\hline Variables & $\begin{array}{c}\text { Patients without } \\
\text { MV Use within } \mathbf{2 4} \mathbf{h} \\
(\boldsymbol{n}=\mathbf{8 7})\end{array}$ & $\begin{array}{c}\text { Patients with } \\
\text { MV Use within } \mathbf{2 4} \mathbf{h} \\
(\boldsymbol{n}=\mathbf{4 4})\end{array}$ & $\boldsymbol{p}$-Value \\
\hline Male & $52(59.8)$ & $23(52.3)$ & 0.527 \\
Female & $35(40.2)$ & $21(47.7)$ & 0.063 \\
Age (years) & $78.0[71.0-84.0]$ & $75.5[61.0-83.0]$ & $<0.001$ \\
SOFA score & $7[5-9]$ & $11[10-13]$ & 0.001 \\
SOFA without respiration score & $6.0 \pm 2.9$ & $7.9 \pm 3.1$ & $<0.001$ \\
Septic shock & $25(28.7)$ & $30(68.2)$ & \\
\hline
\end{tabular}


Table 1. Cont.

\begin{tabular}{|c|c|c|c|}
\hline Variables & $\begin{array}{l}\text { Patients without } \\
\text { MV Use within } 24 \mathrm{~h} \\
(n=87)\end{array}$ & $\begin{array}{l}\text { Patients with } \\
\text { MV Use within } 24 \mathrm{~h} \\
(n=44)\end{array}$ & $p$-Value \\
\hline Infection focus & & & 0.508 \\
\hline Respiratory & $53(60.9)$ & $34(77.3)$ & \\
\hline Genitourinary & $20(23.0)$ & $6(13.6)$ & \\
\hline Gastrointestinal & $10(11.5)$ & $3(6.8)$ & \\
\hline Bacteremia & $2(2.3)$ & $1(2.3)$ & \\
\hline CNS & $1(1.1)$ & $0(0)$ & \\
\hline Catheter-related & $1(1.1)$ & $0(0)$ & \\
\hline \multicolumn{4}{|l|}{ Past medical history } \\
\hline Hypertension & $51(58.6)$ & $21(47.7)$ & 0.318 \\
\hline Diabetes & $41(47.1)$ & $20(45.5)$ & 1.000 \\
\hline Liver disease & $4(4.6)$ & $5(11.4)$ & 0.280 \\
\hline Heart disease & $22(25.3)$ & $6(13.6)$ & 0.190 \\
\hline Cerebrovascular disease & $19(21.8)$ & $10(22.7)$ & 1.000 \\
\hline Lung disease & $6(6.9)$ & $6(13.6)$ & 0.346 \\
\hline Kidney disease & $5(5.7)$ & $6(13.6)$ & 0.229 \\
\hline Malignancy & $24(27.6)$ & $11(25.0)$ & 0.915 \\
\hline \multicolumn{4}{|l|}{ Vital signs } \\
\hline SBP (mmHg) & $99.0[89.0-130.5]$ & 101.5 [75.5-128.0] & 0.321 \\
\hline $\mathrm{DBP}(\mathrm{mmHg})$ & $60.0[51.0-74.0]$ & $57.0[50.0-73.0]$ & 0.277 \\
\hline $\mathrm{RR}(/ \mathrm{min})$ & $23.0[20.0-26.0]$ & $24.0[22.0-28.0]$ & 0.033 \\
\hline $\operatorname{HR}(/ \mathrm{min})$ & $102.2 \pm 29.0$ & $107.1 \pm 29.1$ & 0.367 \\
\hline Body temperature & $37.2 \pm 1.3$ & $37.1 \pm 1.3$ & 0.688 \\
\hline \multicolumn{4}{|l|}{ Laboratory data } \\
\hline Lactate $(\mathrm{mmol} / \mathrm{L})$ & $2.5[1.7-4.5]$ & $4.4[2.4-6.5]$ & 0.005 \\
\hline Procalcitonin (ng/mL) & $1.3[0.5-9.0]$ & $1.9[0.6-15.1]$ & 0.454 \\
\hline Platelet count $\left(\times 10^{3} / \mu \mathrm{L}\right)$ & $209.0[133.5-284.5]$ & $200.5[113.0-294.5]$ & 0.866 \\
\hline White blood cells $\left(\times 10^{3} / \mu \mathrm{L}\right)$ & $11.2[7.8-16.8]$ & $10.6[7.1-17.3]$ & 0.748 \\
\hline $\mathrm{pH}$ & $7.4[7.4-7.5]$ & $7.3[7.2-7.4]$ & $<0.001$ \\
\hline $\mathrm{PCO}_{2}(\mathrm{mmHg})$ & $31.5[27.0-39.6]$ & $38.5[27.4-56.2]$ & 0.017 \\
\hline $\mathrm{PO}_{2}(\mathrm{mmHg})$ & $76.0[60.9-97.5]$ & $67.5[51.0-87.0]$ & 0.030 \\
\hline $\mathrm{HCO}_{3}(\mathrm{mmol} / \mathrm{L})$ & $20.5[17.5-24.1]$ & $19.8[14.4-26.1]$ & 0.936 \\
\hline Glucose (mg/dL) & $140.0[107.5-174.0]$ & $149.0[107.5-214.5]$ & 0.477 \\
\hline Creatinine (mg/dL) & $1.3[0.9-2.0]$ & $1.5[0.9-2.5]$ & 0.594 \\
\hline Bilirubin (mg/dL) & $0.6[0.4-1.1]$ & $0.6[0.3-0.9]$ & 0.434 \\
\hline CRP (mg/dL) & $11.3[6.1-17.6]$ & $10.2[3.9-18.2]$ & 0.533 \\
\hline Albumin (g/dL) & $3.0 \pm 0.6$ & $3.0 \pm 0.9$ & 0.942 \\
\hline $\begin{array}{l}\text { Highly sensitive troponin } \mathrm{T} \\
\text { (ng/mL) }\end{array}$ & $0.1[0.0-0.1]$ & $0.1[0.0-0.2]$ & 0.284 \\
\hline BNP elevation & $40(46.0)$ & $22(50.0)$ & 0.802 \\
\hline \multicolumn{4}{|l|}{ Clinical data } \\
\hline Vasopressor use & $36(41.4)$ & $35(79.5)$ & $<0.001$ \\
\hline $\mathrm{SpO}_{2}$ & $96.0[92.0-98.0]$ & $90.0[82.0-95.0]$ & $<0.001$ \\
\hline Applied $\mathrm{FiO}_{2}$ & $0.4[0.3-0.6]$ & $1.0[0.8-1.0]$ & $<0.001$ \\
\hline $\mathrm{O}_{2}$ supplementation & $73(83.9)$ & $41(93.2)$ & 0.224 \\
\hline High-flow nasal cannula use & $18(20.7)$ & $8(18.2)$ & 0.914 \\
\hline $\mathrm{PaO}_{2} / \mathrm{FiO}_{2}$ ratio & 188.5 [97.5-355.7] & $72.7[51.8-125.6]$ & $<0.001$ \\
\hline ROX index & $10.0[5.9-15.2]$ & $4.0[3.2-5.4]$ & $<0.001$ \\
\hline ROX-HR index & $10.1[5.4-16.3]$ & $3.9[2.7-5.8]$ & $<0.001$ \\
\hline
\end{tabular}

Values are expressed as the mean \pm standard deviation, median [IQR], or number (\%). Abbreviations: $\mathrm{MV}=$ mechanical ventilator, SOFA = sequential organ failure assessment, CNS = central nervous system, GCS $=$ Glasgow coma scale, $\mathrm{SpO}_{2}=$ tissue oxygen saturation, $\mathrm{SBP}=$ systolic blood pressure, $\mathrm{DBP}=$ diastolic blood pressure, $\mathrm{RR}=$ respiratory rate, $\mathrm{HR}=$ heart rate, $\mathrm{PCO}_{2}=$ partial pressure of carbon dioxide, $\mathrm{PO}_{2}=$ partial pressure of oxygen, $\mathrm{HCO}_{3}=$ bicarbonate, $\mathrm{BNP}=$ brain natriuretic peptide, $\mathrm{PaO}_{2}=$ partial pressure of oxygen in alveoli, $\mathrm{ROX}=$ respiratory rate oxygenation, $\mathrm{CRP}=\mathrm{C}$-reactive protein, $\mathrm{FiO}_{2}=$ fraction of inspired oxygen. 


\subsection{ROC Curve of ROX Index and ROX-HR Index for Mechanical Ventilator Use within $24 \mathrm{~h}$}

The area under the ROC (AUROC) curve of the ROX index for mechanical ventilator use within $24 \mathrm{~h}$ was 0.854 (95\% CI: 0.791-0.918, $p<0.001$ ) (Figure 2). The optimal cutoff point was 5.238 , with a sensitivity of $75.0 \%$ and specificity of $81.6 \%$. The AUROC curve of ROX-HR was 0.816 (95\% CI: $0.742-0.890, p<0.001)$. The optimal cutoff point was 5.210, with a sensitivity of $72.7 \%$ and specificity of $77.0 \%$

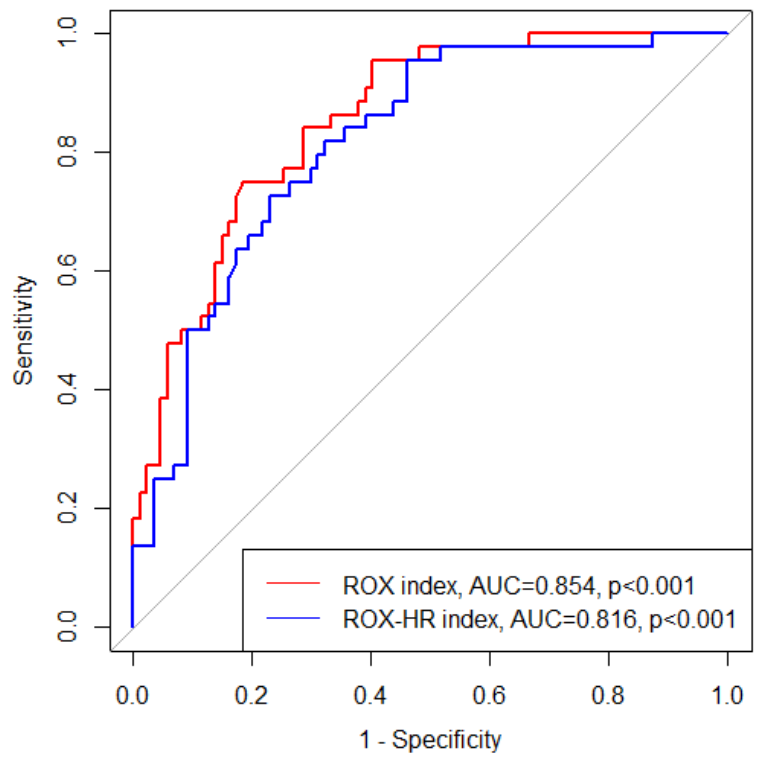

Figure 2. Receiver operating characteristic curve of the ROX index and ROX-HR index for mechanical ventilator use within $24 \mathrm{~h}$. Abbreviations: ROX = respiratory rate oxygenation, AUC = area under curve.

\subsection{Outcomes according to the ROX Index and ROX-HR Index Level}

When the ROX index was grouped according to the optimal cutoff from the ROC curve, the use of mechanical ventilator within $24 \mathrm{~h}$ was significantly higher in the low ROX group than in the high ROX group $(p<0.001)$. The 7-day mortality, 14-day mortality, 28-day mortality, and ICU admissions were also significantly higher in the low ROX group than in the high ROX group $(p<0.05)$ (Table 2).

Table 2. Outcomes according to the ROX index level and ROX-HR index level.

\begin{tabular}{|c|c|c|c|}
\hline Outcomes & High ROX Level & Low ROX Level & $p$-Value \\
\hline MV use within $24 \mathrm{~h}^{1}$ & $11 / 82(13.4)$ & $33 / 49(67.3)$ & $<0.001$ \\
\hline 7-day mortality ${ }^{2}$ & $6 / 84(7.1)$ & $15 / 53(28.3)$ & 0.002 \\
\hline 14-day mortality ${ }^{2}$ & $12 / 84(14.3)$ & $19 / 53(35.8)$ & 0.006 \\
\hline 28 -day mortality ${ }^{2}$ & $13 / 84(15.5)$ & $23(43.4)$ & 0.001 \\
\hline ICU admission $^{1}$ & $42 / 82(51.2)$ & $36 / 49(73.5)$ & 0.020 \\
\hline Outcomes & High ROX-HR Level & Low ROX-HR Level & $p$-Value \\
\hline MV use within $24 \mathrm{~h}^{1}$ & $12 / 79(15.2)$ & $32 / 52(61.5)$ & $<0.001$ \\
\hline 7-day mortality ${ }^{2}$ & $8 / 82(9.8)$ & $13 / 55(23.6)$ & 0.049 \\
\hline 14-day mortality ${ }^{2}$ & $13 / 82(15.9)$ & $18 / 55$ (32.7) & 0.035 \\
\hline 28 -day mortality ${ }^{2}$ & $14 / 82(17.1)$ & $22 / 55(40.0)$ & 0.005 \\
\hline ICU admission ${ }^{1}$ & $39 / 79(49.4)$ & $39 / 52(75.0)$ & 0.006 \\
\hline
\end{tabular}

${ }^{1}$ The study populations $(n=131)$ were analysed. ${ }^{2}$ The patients who died within $24 \mathrm{~h}(n=6)$ were included into the analysis (total 137 patients). Values are expressed as numbers/total number (\%). Abbreviations: MV = mechanical ventilator, ICU $=$ intensive care unit. 
When grouping the ROX-HR index by the cutoff point, the primary outcome was significantly higher in the low ROX-HR group than in the high ROX-HR group $(p<0.001)$. Among the secondary outcomes, 7-day mortality, 14-day mortality, 28-day mortality and ICU admission were significantly higher in the low ROX group than in the high ROX group $(p<0.05)$ (Table 2).

\subsection{Multivariate Cox Proportional Hazard Model}

In the multivariate Cox proportional hazard model using ROX index, ROX index was independently associated with mechanical ventilator use within $24 \mathrm{~h}$ (adjusted hazard ratio $=0.78,95 \%$ CI: 0.68-0.90, $p<0.001$ ), (Figure 3).

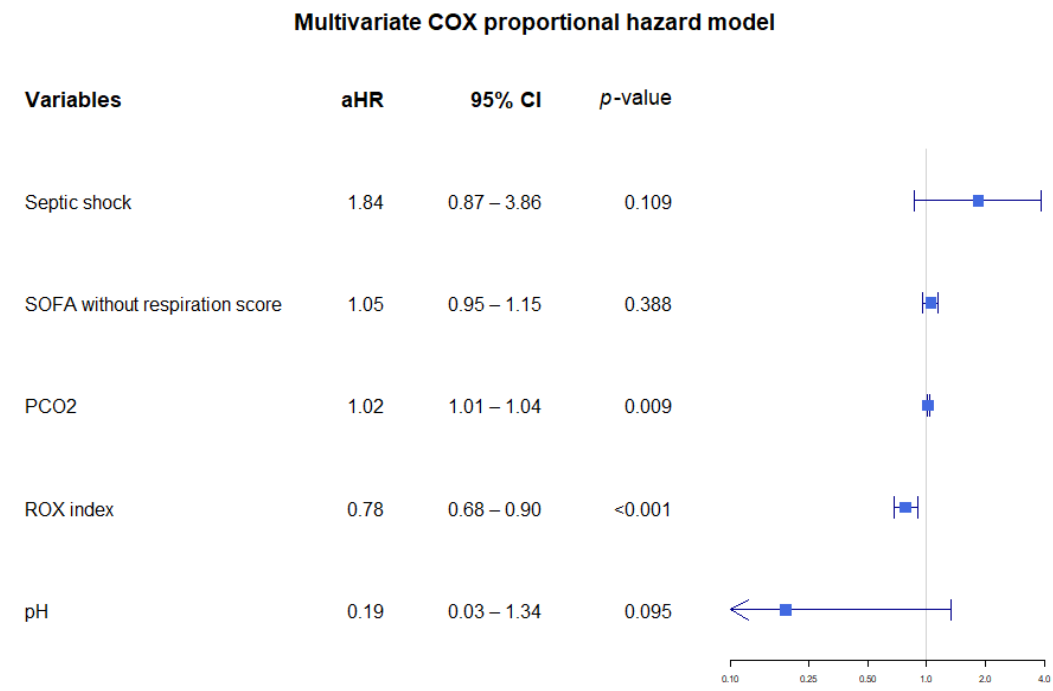

Figure 3. Multivariate cox proportional hazard model using the ROX index. Abbreviations: aHR $=$ adjusted hazard ratio, $\mathrm{CI}=$ confidence interval, SOFA $=$ sequential organ failure assessment, $\mathrm{PCO}_{2}=$ partial pressure of carbon dioxide.

In the multivariate Cox proportional hazard model using ROX-HR index, ROX-HR index was independently associated with mechanical ventilator use within $24 \mathrm{~h}$ (adjusted hazard ratio $=0.87,95 \%$ CI 0.79-0.96, $p=0.004)$, (Figure 4 ).

Multivariate coX proportional hazard model

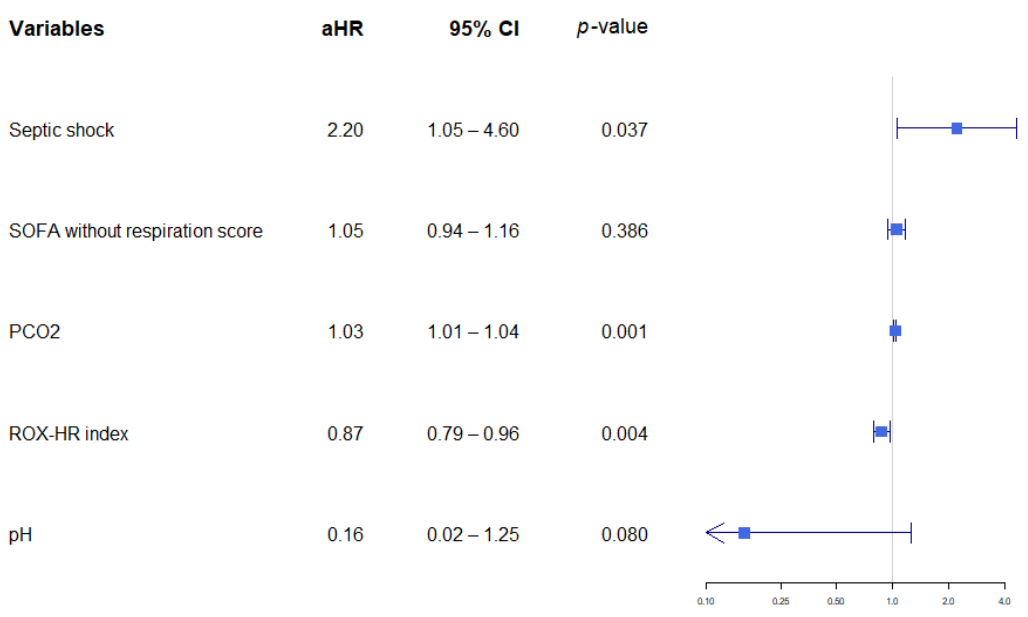

Figure 4. Multivariate cox proportional hazard model using the ROX-HR index. Abbreviations: aHR = adjusted hazard ratio, $\mathrm{CI}=$ confidence interval, SOFA = sequential organ failure assessment, $\mathrm{PCO}_{2}=$ partial pressure of carbon dioxide. 


\subsection{Kaplan-Meier Curve}

Figure 5 shows that mechanical ventilator use within $24 \mathrm{~h}$ was higher in low ROX index and low ROX-HR groups (log-rank test: both $p<0.001)$.
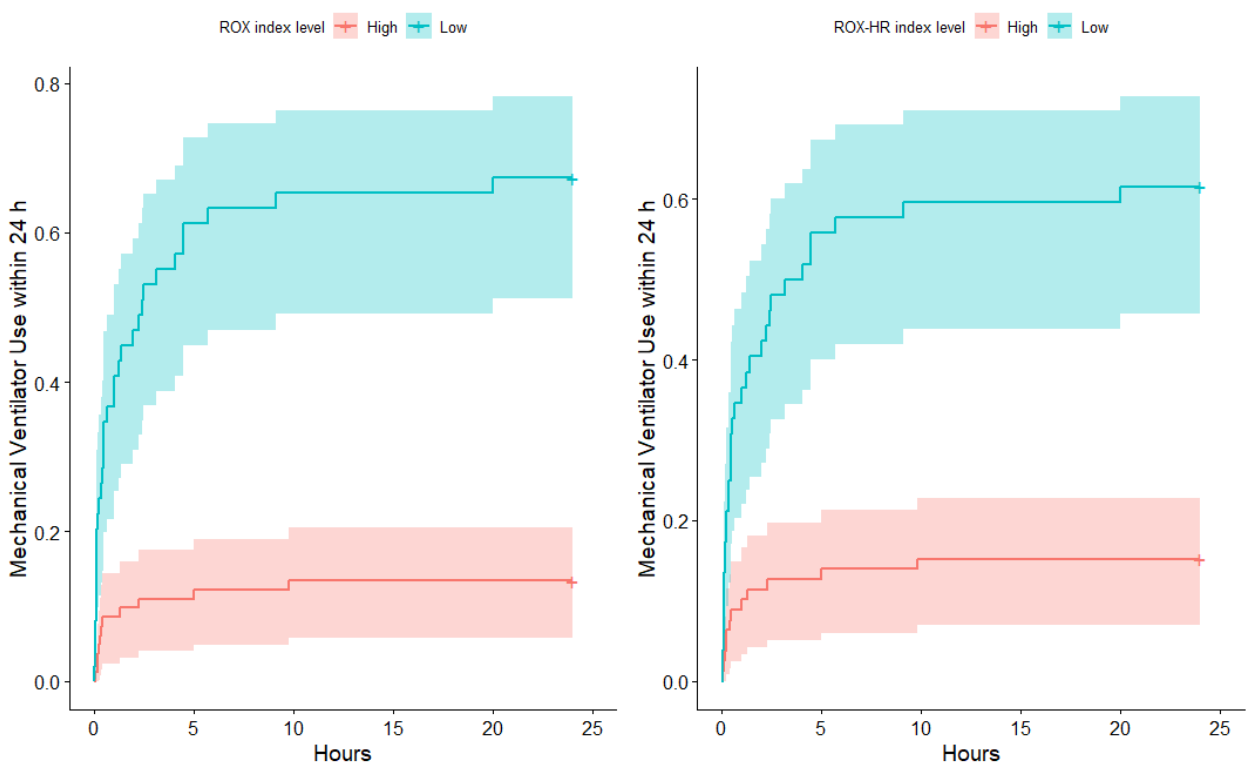

Figure 5. Kaplan-Meier curve for mechanical ventilator use within $24 \mathrm{~h}$ by ROX index (left) and ROX-HR index (right) level.

\subsection{Subgroup Analysis}

The primary origin of infection focus of 87 patients was respiratory cause. Among them, ROX and ROX-HR indices were both lower in patients with mechanical ventilator use within $24 \mathrm{~h}$ than in patients without the use of a mechanical ventilator (3.6 [2.9-4.5] vs. 8.9 [5.5-13.5], $p<0.001$ and 3.6 [2.5-6.3] vs. 7.3 [4.9-13.5], $p<0.001$, respectively). The AUROC curve of ROX index and ROX-HR were 0.844 (95\% CI: 0.760-0.927, $p<0.001$ ) and 0.778 (95\% CI: 0.679-0.877, $p<0.001)$, respectively. ROX index was independently associated with mechanical ventilator use within $24 \mathrm{~h}$ (adjusted hazard ratio $=0.81,95 \% \mathrm{CI}$ : $0.68-0.95, p=0.012$ ), while ROX-HR was not (adjusted hazard ratio $=0.91,95 \%$ CI: $0.82-1.01$, $p=0.071)$.

The primary origin of infection focus of 44 patients was other than respiratory cause. Among them, ROX and ROX-HR indices were both lower in patients with mechanical ventilator use within $24 \mathrm{~h}$ than in patients without the use of a mechanical ventilator (4.9 [4.2-6.2] vs. 11.7 [7.4-19.8], $p<0.001$ and 4.3 [3.3-5.7] vs. 12.9 [6.5-23.9], $p<0.001$, respectively). The AUROC curve of ROX index and ROX-HR were 0.856 (95\% CI: 0.747-0.965, $p<0.001$ ) and 0.882 (95\% CI: 0.782-0.982, $p<0.001)$, respectively. ROX index was independently associated with primary outcome (adjusted hazard ratio $=0.71,95 \%$ CI $0.51-0.99, p=0.049$ ), while ROX-HR was not (adjusted hazard ratio $=0.65,95 \%$ CI $0.37-1.13, p=0.126$ ).

\section{Discussion}

The ROX and ROX-HR indices in qSOFA-positive sepsis patients in the ED were independently associated with mechanical ventilator use within $24 \mathrm{~h}$. The AUROC curves of the ROX and ROX-HR indices for mechanical ventilator use within $24 \mathrm{~h}$ showed good values (0.854 and 0.816, respectively). According to the optimal cutoff, the low ROX and low ROX-HR groups were also associated with short-term mortality.

Critical patients on mechanical ventilation require considerable medical resources [15]. In sepsis patients, mechanical ventilation is also a component of the respiratory evaluation of the SOFA score, which is associated with mortality [6]. It is important to identify patients at a high-risk of mechanical ventilator use in emergency settings. 
The $\mathrm{PaO}_{2} / \mathrm{FiO}_{2}$ ratio is traditionally used to assess oxygenation in patients with acute respiratory failure, especially for diagnosing acute lung injury or acute respiratory distress syndrome [16]. Obtaining $\mathrm{PaO}_{2}$ from patients requires arterial blood sampling. $\mathrm{SpO}_{2}$ can be obtained non-invasively using pulse oximetry and correlates well with $\mathrm{PaO}_{2}$ in the range of $80-100 \%$ [17]. Rice et al. revealed that the $\mathrm{SpO}_{2} / \mathrm{FiO}_{2}$ ratio correlated with the $\mathrm{PaO}_{2} / \mathrm{FiO}_{2}$ ratio in patients with acute lung injury or acute respiratory failure $(\mathrm{r}=0.89$, $p<0.001$ ) [18]. Roca et al. studied the association of indexes with high-flow nasal cannula failure, defined as mechanical ventilator use in patients with acute respiratory failure in the ICU $[9,10]$. They combined the $\mathrm{SpO}_{2} / \mathrm{FiO}_{2}$ ratio with $\mathrm{RR}$, which showed an association with mechanical ventilator use. They named the ratio of $\mathrm{SpO}_{2} / \mathrm{FiO}_{2}$ to $\mathrm{RR}$ as the $\mathrm{ROX}$ (respiratory rate oxygenation) index. Goh et al. then introduced the ROX-HR index by adding HR with the ROX index [11]. Both ROX and ROX-HR indices can be obtained easily and non-invasively, especially in triage or at the bedside.

The ROX index is useful for identifying patients at risk of mechanical ventilation in critical settings. Two studies by Roca et al. have reported that the ROX index can be used to predict the need for mechanical ventilator use in patients with hypoxemic acute respiratory failure using a high-flow nasal cannula in ICUs [9,10]. Our study showed a higher AUROC curve than previous studies (0.740 and 0.752) using the initially measured ROX index. The optimal cutoff point was similar to that reported previously. Compared to previous studies showing independent association between mechanical ventilator use and ROX index as categorical variable, we found an independent association of ROX index with use of a mechanical ventilator as a continuous variable (adjusted hazard ratio $=0.78$, 95\% CI: $0.68-0.90, p<0.001)$. The inclusion criteria of initial qSOFA-positive patients might have contributed to the higher AUROC curve, even though the initial ROX index was considered. It is also possible that patients in the ICU received initial resuscitation in the ED or general wards before admission to ICU, which may contribute to the difference in the AUROC curve. The ROX index might be a more promising tool for identifying high-risk patients in an ED than in ICU.

The ROX-HR index is a modified ROX index that adds HR to the ROX index. Goh et al. have reported ROX-HR index as a better tool for identifying mechanical ventilator use in acute hypoxemic failure patients with high-flow nasal cannula [11]. However, our study showed a greater AUROC curve for the ROX index than the ROX-HR index (0.854 vs. 0.816, $p=0.020$ ). This might be explained by the fact that the HR of our population did not differ significantly between the groups, whereas the HR was significantly higher in the group with mechanical ventilator use in a previous study. For patients who are qSOFA-positive sepsis in the ED, the ROX index might be a better tool to predict mechanical ventilator use within $24 \mathrm{~h}$ than ROX-HR index. Pimentel et al. reported that HR did not change significantly in critical COVID-19 patient those with low $\mathrm{SpO}_{2}$ and high $\mathrm{FiO}_{2}$ [19]. This reflects that ROX index might be a better index to predict mechanical ventilator use in critical COVID-19 patient than ROX-HR index.

In previous studies, both ROX and ROX-HR indices at delayed time points, especially at 10 and $12 \mathrm{~h}$, showed a better AUROC curve [9-11]. Further research is warranted to determine the ROX and ROX-HR index values in the ED at different time points, such as 2, $6,10,12 \mathrm{~h}$, and beyond.

ROX index might be a fine tool to predict mechanical ventilator use within $24 \mathrm{~h}$ regardless of infection focus. The AUROC curves of ROX index were similar between subgroups and whole study population. ROX index showed independent association with mechanical ventilator use in both subgroups, while ROX-HR did not. The AUROC curve of ROX-HR index was smaller in patients with primary infection of respiratory cause than whole study population. For those with respiratory infection, the changes of HR might be not significant in those who need mechanical ventilation. Therefore, ROX index might be a better index to predict mechanical ventilator use than ROX-HR index, especially in patients with respiratory infection. 
The ROX and ROX-HR indices can be used as additional tools for identifying sepsis patients with a high-risk of mortality in the ED. Lee et al. reported that a ROX index of less than ten was independently associated with mortality in sepsis patients in the ED (adjusted hazard ratio 1.41) [12]. Our study showed that the low ROX index group and the low ROX$\mathrm{HR}$ index group were associated with short-term mortality in sepsis patients, supporting the results of a previous study. Respiratory dysfunction can decrease the $\mathrm{SpO}_{2} / \mathrm{FiO}_{2}$ ratio and increase RR. Renal dysfunction and acidosis in sepsis can also increase RR due to compensation. The association of the ROX index with mortality in sepsis patients can be explained by these mechanisms. To the best of our knowledge, the association of the ROX-HR index with mortality in sepsis has not yet been reported. Further studies are warranted to determine whether ROX-HR is associated with mortality in sepsis patients.

This study had several limitations. First, the factors that can affect mechanical ventilator use might have been missed due to the retrospective observational nature of this study. Second, actual inspired $\mathrm{FiO}_{2}$ was not obtained in our study. True inspired $\mathrm{FiO}_{2}$ is influenced by minute ventilation when using reservoir mask, simple mask, and nasal prong [20]. The actual minute ventilation of the patients was not obtained and not able to be calculated in our study. Therefore, $\mathrm{FiO}_{2}$ is estimated by assumption of linear correlations between calculated $\mathrm{FiO}_{2}$ and delivered flow rate of oxygen for reservoir mask, simple mask, and nasal prong. True inspired $\mathrm{FiO}_{2}$ might be different from estimated $\mathrm{FiO}_{2}$. Third, this study was performed at a single ED. Further multicenter studies are needed to generalize these results. Fourth, initial qSOFA-positive sepsis patients were included. The result cannot be generalized to initial qSOFA-negative or delayed qSOFA-positive sepsis patients. Further studies including the ROX index and ROX-HR value in initial qSOFA-negative or delayed qSOFA-positive sepsis patients are warranted. Fifth, the initial values from arrival to the ED were used for analysis. The roles of the ROX and ROX-HR indices at $6 \mathrm{~h}, 12 \mathrm{~h}$, and beyond have not been determined and require further investigation. Sixth, 18 patients were excluded due to missing laboratory data that are needed for SOFA score or ROX index calculation. Most of them were excluded due to missing initial $\mathrm{SpO}_{2}$. This might be due to poor sensing of $\mathrm{SpO}_{2}$ upon arrival at ED. One patient had missing laboratory data for SOFA score calculation. The patient's lab was performed on outpatient department, which is few days before arrival at the ED. The patient did not have any symptoms at outpatient department. The patient refused blood chemistry lab at the ED, admitted without any lab test at ED, and died on Hospital Day 3. We decided to exclude this patient because the lab result at outpatient department might not reflect true condition upon arrival to the ED. Seventh, the patients who died within $24 \mathrm{~h}$ were excluded in this study. Some patients might experience cardiac arrest without return of spontaneous circulation within $24 \mathrm{~h}$. These patients might receive intubation but failed to use mechanical ventilator. These patients could influence the result. However, the results were similar when the patients who died within $24 \mathrm{~h}$ were included in analysis.

\section{Conclusions}

The ROX and ROX-HR indices were associated with mechanical ventilator use within $24 \mathrm{~h}$ in qSOFA-positive patients in the ED. ROX and ROX-HR indices were also associated with short-term mortality.

Supplementary Materials: The following are available online at https: / www.mdpi.com/article / 10.3390/jcm11020342/s1, Table S1: univariate Cox proportional hazard model.

Author Contributions: Conceptualization, S.A. and S.M.; methodology, S.A.; formal analysis, S.A., J.P. and J.S.; data curation, S.A., J.K. and H.C.; writing-original draft preparation, S.A. and S.M.; writing - review and editing, S.A. and S.M.; visualization, S.A. and J.K.; supervision, S.M. All authors have read and agreed to the published version of the manuscript.

Funding: This research received no external funding. 
Institutional Review Board Statement: The study was conducted according to the guidelines of the Declaration of Helsinki, and approved by the Institutional Review Board (or Ethics Committee) of Korea University (2021AS0057).

Informed Consent Statement: Patient consent was waived due to its retrospective design.

Data Availability Statement: The data presented in this study are available on request from the corresponding author. The data are not publicly available due to their containing information that could compromise the privacy of research participants.

Conflicts of Interest: The authors declare no conflict of interest.

\section{References}

1. Singer, M.; Deutschman, C.S.; Seymour, C.W.; Shankar-Hari, M.; Annane, D.; Bauer, M.; Bellomo, R.; Bernard, G.R.; Chiche, J.-D.; Coopersmith, C.M.; et al. The Third International Consensus Definitions for Sepsis and Septic Shock (Sepsis-3). JAMA 2016, 315, 801-810. [CrossRef] [PubMed]

2. Esteban, A.; Anzueto, A.; Frutos-Vivar, F.; Alía, I.; Brochard, L.; Stewart, T.E.; Benito, S.; Epstein, S.K.; Apezteguía, C.; Nightingale, P.; et al. Characteristics and Outcomes in Adult Patients Receiving Mechanical VentilationA 28-Day International Study. JAMA 2002, 287, 345-355. [CrossRef]

3. Fuller, B.M.; Mohr, N.M.; Miller, C.N.; Deitchman, A.R.; Levine, B.J.; Castagno, N.; Hassebroek, E.C.; Dhedhi, A.; Scott-Wittenborn, N.; Grace, E.; et al. Mechanical Ventilation and ARDS in the ED: A multicenter, observational, prospective, cross-sectional study. Chest 2015, 148, 365-374. [CrossRef]

4. $\quad$ Mikkelsen, M.E.; Shah, C.V.; Meyer, N.J.; Gaieski, D.F.; Lyon, S.; Miltiades, A.N.; Goyal, M.; Fuchs, B.D.; Bellamy, S.L.; Christie, J. The Epidemiology of Acute Respiratory Distress Syndrome in Patients Presenting to the Emergency Department with Severe Sepsis. Shock 2013, 40, 375-381. [CrossRef]

5. Fuller, B.M.; Mohr, N.M.; Dettmer, M.; Kennedy, S.; Cullison, K.; Bavolek, R.; Rathert, N.; McCammon, C. Mechanical Ventilation and Acute Lung Injury in Emergency Department Patients with Severe Sepsis and Septic Shock: An Observational Study. Acad. Emerg. Med. 2013, 20, 659-669. [CrossRef] [PubMed]

6. Rhodes, A.; Evans, L.E.; Alhazzani, W.; Levy, M.M.; Antonelli, M.; Ferrer, R.; Kumar, A.; Sevransky, J.E.; Sprung, C.L.; Nunnally, M.E.; et al. Surviving Sepsis Campaign: International Guidelines for Management of Sepsis and Septic Shock: 2016. Intensive Care Med. 2017, 43, 304-377. [CrossRef]

7. Gotts, J.E.; Matthay, M.A. Sepsis: Pathophysiology and clinical management. BMJ 2016, 353, i1585. [CrossRef] [PubMed]

8. Zampieri, F.; Mazza, B. Mechanical Ventilation in Sepsis: A reappraisal. Shock 2017, 47 (Suppl. 1), 41-46. [CrossRef] [PubMed]

9. Roca, O.; Messika, J.; Caralt, B.; de Acilu, M.G.; Sztrymf, B.; Ricard, J.-D.; Masclans, J.R. Predicting success of high-flow nasal cannula in pneumonia patients with hypoxemic respiratory failure: The utility of the ROX index. J. Crit. Care 2016, 35, 200-205. [CrossRef] [PubMed]

10. Roca, O.; Caralt, B.; Messika, J.; Samper, M.; Sztrymf, B.; Hernández, G.; García-De-Acilu, M.; Frat, J.-P.; Masclans, J.R.; Ricard, J.-D. An Index Combining Respiratory Rate and Oxygenation to Predict Outcome of Nasal High-Flow Therapy. Am. J. Respir. Crit. Care Med. 2019, 199, 1368-1376. [CrossRef] [PubMed]

11. Goh, K.J.; Chai, H.Z.; Ong, T.H.; Sewa, D.W.; Phua, G.C.; Tan, Q.L. Early prediction of high flow nasal cannula therapy outcomes using a modified ROX index incorporating heart rate. J. Intensiv. Care 2020, 8, 41. [CrossRef] [PubMed]

12. Lee, C.U.; Jo, Y.H.; Lee, J.H.; Kim, J.; Park, S.M.; Hwang, J.E.; Lee, D.K.; Park, I.; Jang, D.-H.; Lee, S.-M. The index of oxygenation to respiratory rate as a prognostic factor for mortality in Sepsis. Am. J. Emerg. Med. 2020, 45, 426-432. [CrossRef] [PubMed]

13. Park, J.; Ahn, S.; Lee, S.; Song, J.; Moon, S.; Kim, J.; Cho, H. Association of ischemia modified albumin with mortality in qSOFA positive sepsis patients by sepsis-3 in the emergency department. Am. J. Emerg. Med. 2021, 44, 72-77. [CrossRef] [PubMed]

14. O'Driscoll, B.R.; Howard, L.S.; Earis, J.; Mak, V.; British Thoracic Society Emergency Oxygen Guideline Group. BTS guideline for oxygen use in adults in healthcare and emergency settings. Thorax 2017, 72 (Suppl. 1), ii1-ii90. [CrossRef] [PubMed]

15. Arefian, H.; Heublein, S.; Scherag, A.; Brunkhorst, F.M.; Younis, M.Z.; Moerer, O.; Fischer, D.; Hartmann, M. Hospital-related cost of sepsis: A systematic review. J. Infect. 2017, 74, 107-117. [CrossRef] [PubMed]

16. Fan, E.; Brodie, D.; Slutsky, A.S. Acute Respiratory Distress Syndrome. JAMA 2018, 319, 698-710. [CrossRef] [PubMed]

17. Jensen, L.A.; Onyskiw, J.E.; Prasad, N. Meta-analysis of arterial oxygen saturation monitoring by pulse oximetry in adults. Hear. Lung 1998, 27, 387-408. [CrossRef]

18. Rice, T.W.; Wheeler, A.P.; Bernard, G.R.; Hayden, D.L.; Schoenfeld, D.A.; Ware, L.B. Comparison of the $\mathrm{Spo}_{2} / \mathrm{Fio}_{2} \mathrm{Ratio}_{\mathrm{and}}$ the $\mathrm{PaO}_{2} / \mathrm{Fio}_{2}$ Ratio in Patients with Acute Lung Injury or ARDS. Chest 2007, 132, 410-417. [CrossRef] [PubMed]

19. Pimentel, M.A.; Redfern, O.C.; Hatch, R.; Young, J.D.; Tarassenko, L.; Watkinson, P.J. Trajectories of vital signs in patients with COVID-19. Resuscitation 2020, 156, 99-106. [CrossRef] [PubMed]

20. Bateman, N.T.; Leach, R.M. ABC of Oxygen: Acute oxygen therapy. BMJ 1998, 317, 798-801. [CrossRef] [PubMed] 